\title{
LOADING OF VERTICAL WALLS BY OVERTOPPING BORES USING PRESSURE AND FORCE SENSORS - A LARGE SCALE MODEL STUDY
}

\author{
Karunya Ramachandran ${ }^{1}$, Rebeca Roldan Genzalez', Hocine Oumeraci', Stefan Schimmels', \\ Matthias Kudella ${ }^{1}$, Koen Van Doorslaer ${ }^{2}$, Julien De Rouck ${ }^{2}$, Tom Versluys ${ }^{2}$ and Koen Trouw ${ }^{3}$ \\ This study is based on the data obtained from tests carried out in the Large Wave Flume (Grosser Wellenkanal \\ $(\mathrm{GWK}))$ in Hannover in the frame of a joint research project of Ghent University (Belgium) and Forschungszentrum \\ Küste (FZK, Germany). The goal of the research project is to determine the wave induced loads on vertical storm \\ walls located at the end of overtopped dike, which are designed to protect coastal cities from overtopping and floods. \\ The loads resulting from waves overtopping the dike and impacting the vertical wall as a bore are measured by means \\ of both force and pressure sensors. This paper describes the results of pressure and force records at the vertical wall, \\ including a comparative analysis of the overall forces obtained by pressure integration and force sensors for two \\ different wall setups: Fully blocked wall and partially blocked wall.
}

Keywords: storm wall; wave overtopping; overtopping bore; impact loads; layer thickness; residual water layer

\section{INTRODUCTION}

Sea dikes are commonly built along the Belgian coast for coastal defence combined with recreational promenade. Wide crested dikes are therefore typical in the region of Flanders, which have a width of several tens of meters, in contrast to the typical grass dikes in rural areas that have a crest width of only few meters. A typical geometry of the Belgian coastline is shown in Fig. 1 (left): a sandy beach in front of a steep dike (slope $1 / 2$ to $1 / 3$ ), followed by a promenade and buildings. However, during a storm with high return period, the expected storm water level can reach the slope of the dike, which allows waves to overtop this structure (Fig. 1, right). This could flood the cities which are lying below the mean sea level.
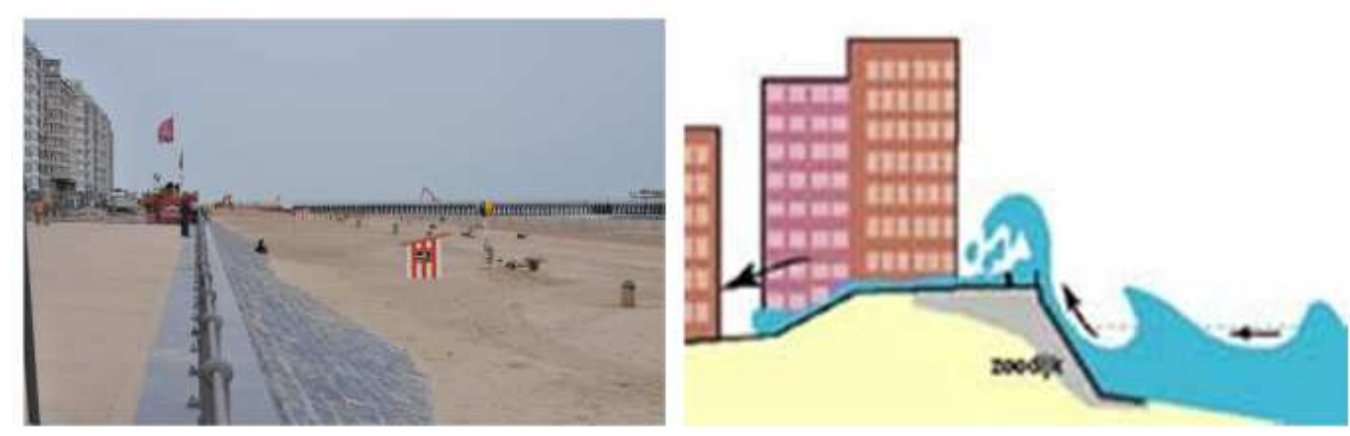

Figure 1. Typical promenade at the Belgian coastline (left) and the situation during storm (right).

Storm walls are an effective and efficient measure to minimize the coastal flood risks in several coastal cities in Belgium. The wide crested dikes along the Belgian coasts offer considerable space for building these storm walls, without too much interference with the daily use of the promenade. Therefore, in several coastal cities in Belgium, storm walls are designed to be located at their most efficient position to reduce wave overtopping: at the end of the existing promenade. Due to the crest width of the dikes, kinetic energy is dissipated on the crest and water flows back towards the sea. The reduction in the overtopping volume due to the crest width is studied by Verwaest et.al (2010).

A schematized description of the problem is illustrated in Fig. 2. The storm wall is not directly subjected to the wave impacts, but to the impacts of the overtopping bore. Therefore, the design of such storm walls requires an estimation of the hydrodynamic loading due to an overtopping bore. Currently, empirical formulae are available to estimate the force induced by broken waves on a wall with a

\footnotetext{
${ }^{1}$ Forschungszentrum Küste, Leibniz University of Hannover, Merkurstraße 11, Hannover, 30419, Germany. ramachandran@fzk-nth.de

${ }^{2}$ Department of Civil Engineering, Ghent University, Technologiepark 904, B-9052, Zwijnaarde, Belgium. koen.vandoorslaer@ugent.be

${ }^{3}$ Coastal Division, Ministry of Flemish Government, Vrijhavenstraat 3, B-8400 Oostende, Belgium.

koen.trouw@mow.vlaanderen.be
} 
sloping foreshore (e.g. CEM, 2003), but no formula exists for the post overtopping wave loads, which motivated the current experimental research project.

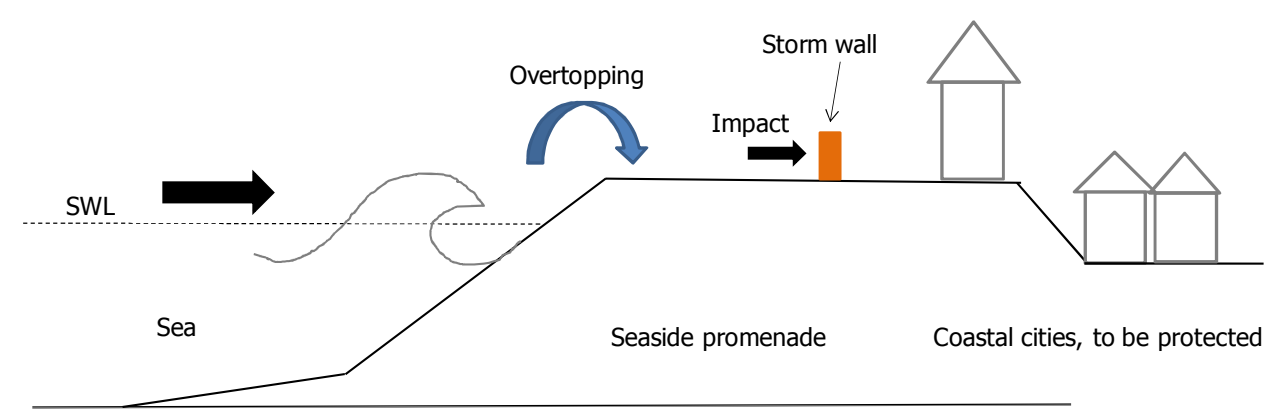

Figure 2. Overtopping bore impact on a storm wall: Principle sketch

A joint research project between Ghent University (Belgium) and Forschungstentrum Küste (FZK, Germany) was carried out in the Large Wave Flume (Grosse Wellenkanal (GWK)) in Hannover. The goal of the project is to determine the impact loads on the storm wall due to overtopping waves.

Apart from the large scale experiments in Hannover, small scale experiments were carried out in the wave flume of Ghent University and at full scale experiments were conducted using the wave overtopping simulator in Tielrode (Belgium). An overview of the different test campaigns can be found in Van Doorslaer et.al (2012). A final test campaign is scheduled in the large-scale flume in Barcelona (CIEM, Universitat Politècnica de Catalunya), as a part of the HYDRALAB IV programme.

The current paper is the first paper describing the GWK-tests, and focuses on the load measurements on the vertical wall by means of both pressure and force sensors under two different model setups: fully blocked wall and partially blocked wall. A comparative analysis of the results of the pressure and force sensors is performed for each model setup. Apart from determining the impact load, some information is gained on the force distribution over the wall height by means of the pressure sensors. In this paper, only regular wave tests were considered, since this work focuses on the force and pressure recordings, and their similarities or differences. The current paper does not focus on the relationship between impacts and wave condition, which requires irregular waves as treated in the second paper by De Rouck et al. (2012).

To have a better understanding of the hydraulic behavior of the overtopping bore, the flow depths, flow velocities and the overtopping discharges along the crest are described under regular wave conditions, in a final paper, Ramachandran et al. (2012).

\section{EXPERIMENTAL SETUP}

The Large Wave Flume (GWK) in Hannover has a length of about $300 \mathrm{~m}$, a width of $5 \mathrm{~m}$ and a depth of $7 \mathrm{~m}$. All the tests were carried out at 1:1 scale on a dike with a slope of 1:3 and crest height of $6.5 \mathrm{~m}$ followed by a horizontal section of about $10 \mathrm{~m}$. The cross section of the dike along with the vertical storm wall is shown in Fig. 3.

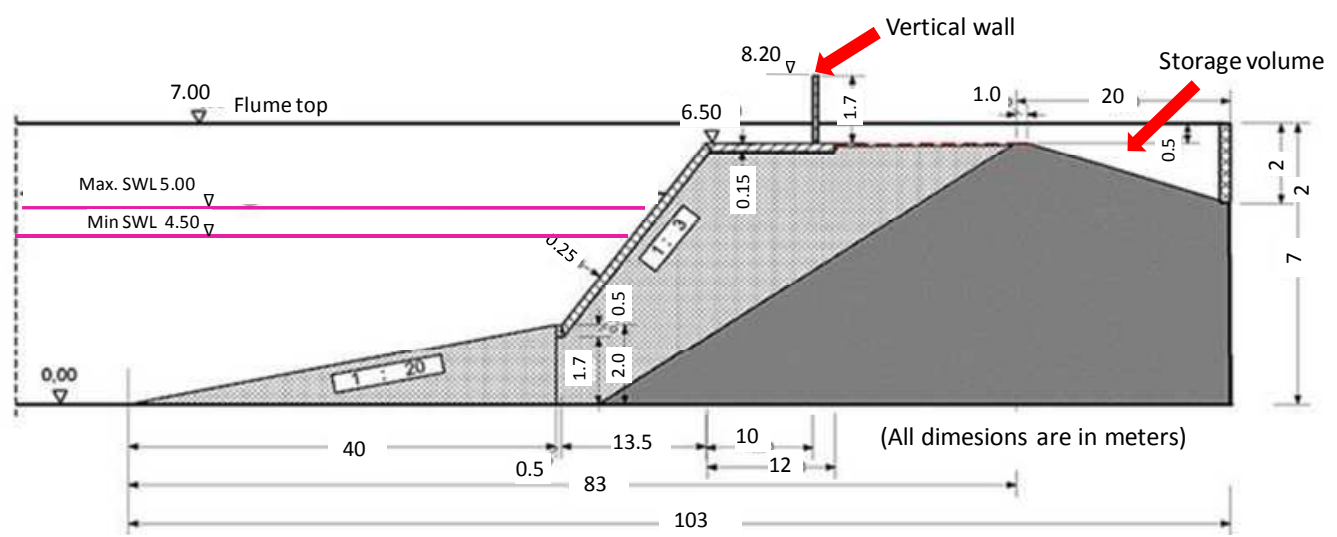

Figure 3. Cross-section of a sea dike with a storm wall in the Large Wave Flume (GWK), Hannover 
The entire dike is constructed with concrete tiles. At the end of the dike crest, vertical walls are installed with measuring and observation equipment including force and pressure sensors to measure the impact forces due to overtopping bore and video to record the overtopping bore kinematics. The horizontal section behind the storm wall followed by a storage container is used to collect the overtopping water and pump it back into the flume. The two storm walls (left wall, right wall, see Fig. 4) are made of aluminium plates equipped with force and pressure sensors. Timber plates are used only to fill up the gaps and to get a continuous wall (see Fig. 4); there are no measurements conducted at these timber plates.

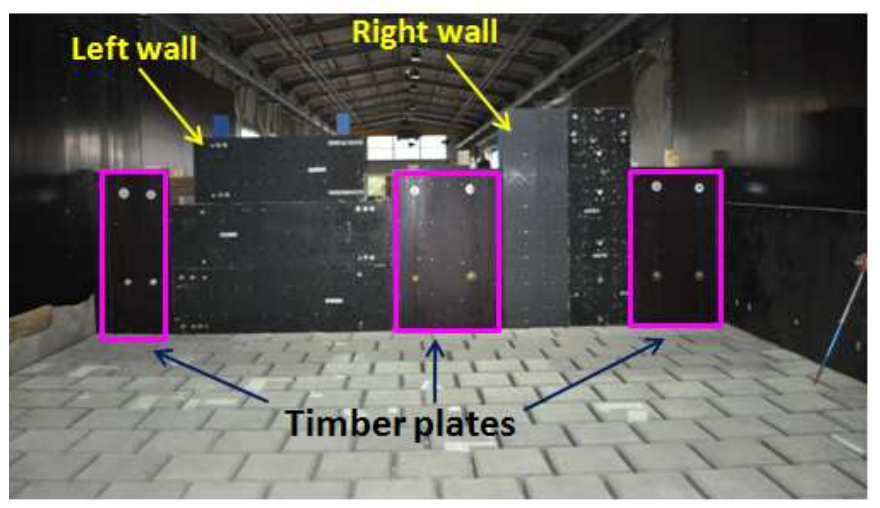

Figure 4. Model setup "fully blocked wall" on the dike crest (Instrumentation of left and right wall see Fig. 5)

The positions of the force and pressure sensors on the wall are shown in Fig. 5. The left wall in Fig. 4 consists of three horizontal plates of each $0.5 \mathrm{~m}$ height. Each plate is attached to four load cells, one in each corner, and is free of contact with the ground or the plates above/below. This is to avoid the forces being transferred to the ground/other plates without being registered by the force sensors of the actual plate. The right wall in Fig. 4 consists of two vertical plates of $1.7 \mathrm{~m} \times 0.5 \mathrm{~m}$, the left one is equipped with two different types of flush mounted pressure sensors (ABHP and PDCR), placed on two vertical arrays in parallel. Each array consists of 8 pressure transducers installed at a $20 \mathrm{~cm}$ interval. The right plate is equipped with four force sensors, one in each corner.

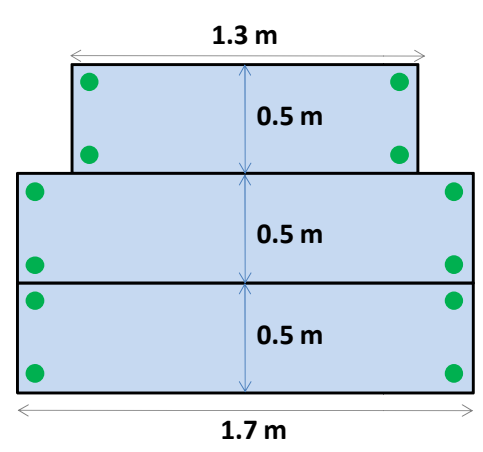

(a) Left wall

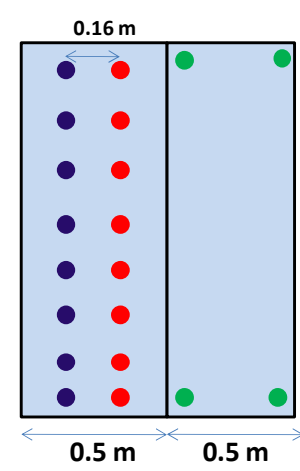

(b) right wall

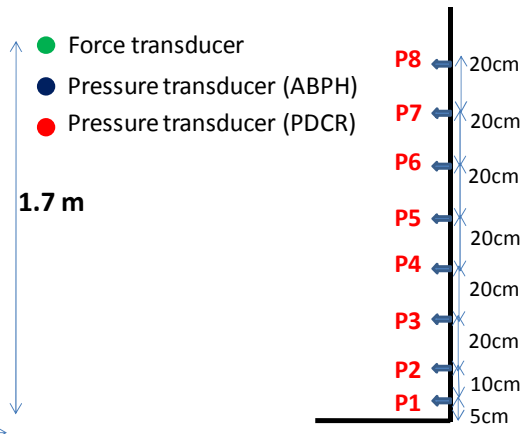

(c) Pressure Sensors $\mathbf{P}$

Figure 5. Positions of the force and pressure sensors on the left (a) and right (b) wall as shown in Fig. 4

Simultaneous measurements are conducted with force and pressure sensors at a sampling frequency of $2000 \mathrm{~Hz}$. In addition to the forces, the following measurements are also obtained during the experiments:

- Flow depths of the overtopping bore along the dike crest;

- Flow velocity of the overtopping bore along the dike crest;

- Incoming wave heights and wave periods at the toe of the dike;

- Video records of the overtopping bore. 
The relationship between the overtopping flow parameters (i.e flow depths, flow velocities and the overtopping discharge) and the impact loads at the vertical wall under regular waves are described in Ramachandran et.al (2012); the results of the irregular waves are reported by De Rouck et.al (2012).

As shown in Fig. 5b, the pressure measurements on the left wall are conducted by means of two different types of sensors: PDCR and ABHP pressure transducers. The results obtained from both sensors are analyzed together with the video observations. However, the pressure-time histories obtained from the ABHP sensors do not follow the physical processes related to the wave impact observed during the experiment very well. The reason for this behaviour is due to the response of ABHP sensors being significantly influenced by the temperature variation during the impact. Therefore, the ABHP sensor results are excluded from the further analysis. All pressure results presented here are based on the data recorded by the PDCR sensors.

\section{TEST CONDITIONS}

The tests were performed with both regular waves and JONSWAP spectra, with wave heights ranging from $1 \mathrm{~m}$ to $1.6 \mathrm{~m}$, periods of $6 \mathrm{~s}$ to $12 \mathrm{~s}$, and free board of $1.5 \mathrm{~m}$ and $2 \mathrm{~m}$ relative to the dike crest (see Fig. 3). Only regular waves (see Table 1) are focused in the present study. The results for the irregular wave tests are reported by De Rouck et.al (2012). The experiments are conducted for two different wall setups:

- Fully blocked wall (gaps between the walls are closed)

- Partially blocked wall (the timber plates are removed)

\begin{tabular}{|c|c|c|c|c|c|}
\hline \multicolumn{7}{|c|}{ Table 1. Test programme } \\
\hline Wall setup & Test.No & $\mathrm{H}_{\text {nom }}(\mathrm{m})$ & $\mathrm{Tp}(\mathrm{s})$ & $\mathrm{WL}(\mathrm{m})$ & $\mathrm{Rc}(\mathrm{m})$ \\
\hline & 01 & 1.20 & 6 & 4.5 & 2.0 \\
Fully blocked & 02 & 1.60 & 6 & 4.5 & 2.0 \\
wall & 03 & 1.13 & 9 & 4.5 & 2.0 \\
& 04 & 1.50 & 9 & 4.5 & 2.0 \\
\hline & $05^{*}$ & 1.13 & 9 & 4.5 & 2.0 \\
& $06^{*}$ & 1.50 & 9 & 4.5 & 2.0 \\
Partially & 07 & 0.85 & 12 & 4.5 & 2.0 \\
blocked wall & 08 & 1.28 & 12 & 4.5 & 2.0 \\
& 09 & 1.20 & 10 & 5.0 & 1.5 \\
& 10 & 1.20 & 6 & 5.0 & 1.5 \\
& 11 & 1.20 & 8 & 5.0 & 1.5 \\
& 12 & 1.20 & 12 & 5.0 & 1.5 \\
\hline
\end{tabular}

*repetition of tests 03 and 04 respectively

As can be seen in Table .1, there are two tests with similar wave conditions for both fully and partially blocked wall set ups which can be used for a comparative analysis of the results obtained from both model set ups (Tests no. $03 \& 05$ and Tests no $04 \& 06$ ).
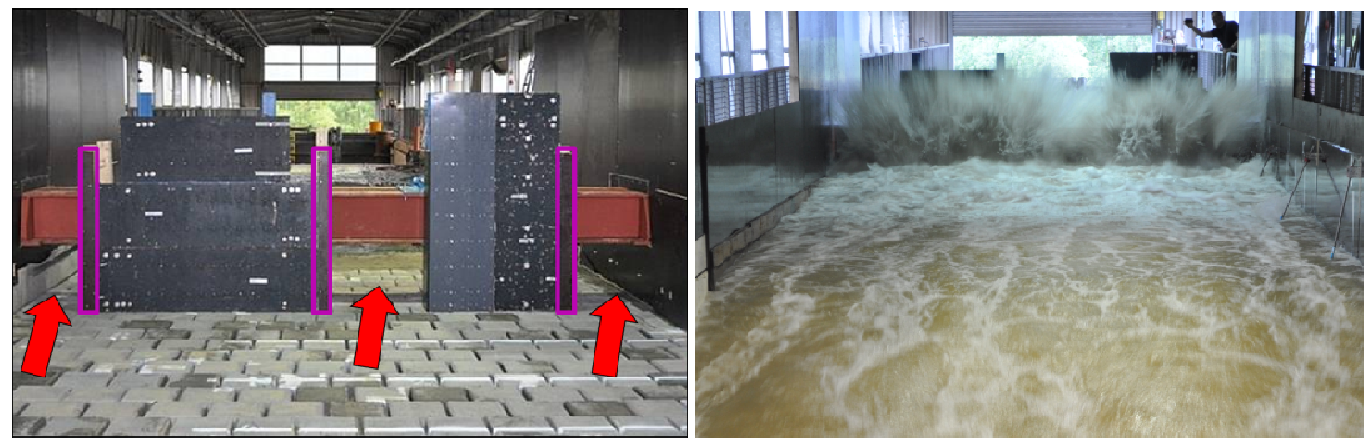

Figure 6. Partially blocked wall setup (left) and overtopping bore impacts on the wall (right)

The "fully blocked wall" set up is shown in Fig. 4. The reflection on the wall was very high and also a thick water layer on the crest was observed after the first overtopping event until the end of the experiment, since the water could not evacuate. The residual water layer in front of the wall can eventually damp the impact, so that a significant reduction of the impact forces may result. 
Furthermore, several high waves were observed near the wave paddle due to very high reflection at the wall. Since we wanted to measure the most critical wave loads (without too much damping due to the residual water layer) and no high wave could be generated (or the paddle would be overtopped, disturbing the wave maker), the timber plates were then removed, so that the water is allowed to evacuate in between two impacts through the gaps. However, a $10 \mathrm{~cm}$ width of strips are installed along the edges of the wall (see Fig. 6 left) to minimize the side wall effects on the measurements of the force sensors. This condition is referred as partially blocked wall. The main idea of this setup is to reduce the reflection on the wall and reduce the thickness of the residual water layer. An example of overtopping bore impacting at the vertical wall during the experiment is shown in Fig. 6 (right).

\section{RESULTS}

\section{Hydrodynamic processes}

The principle sketch in Fig. 7 is to illustrate the main hydrodynamic process during the overtopping bore impacts on the vertical wall. As the wave progresses towards the structure, first wave breaking occurs at the dike slope, followed by overtopping over the crest due to wave run-up. A turbulent bore propagates towards the wall eventually inducing an impact load. Immediately after the impact, reflection occurs, and the water layer flows back to the flume. The arrows in Fig. 5 indicate that the flow occurs in both directions due to incoming bore and the reflected water layer. In the case of wave conditions with a short period in between two consecutive overtopping events, the reflected water layer interacts with the subsequent incoming bore before it flows back to the flume. This was always the case for the regular waves, so there has been a remaining water layer along the crest throughout all experiments with regular waves. This is discussed in more detail by Ramachandran et.al (2012).

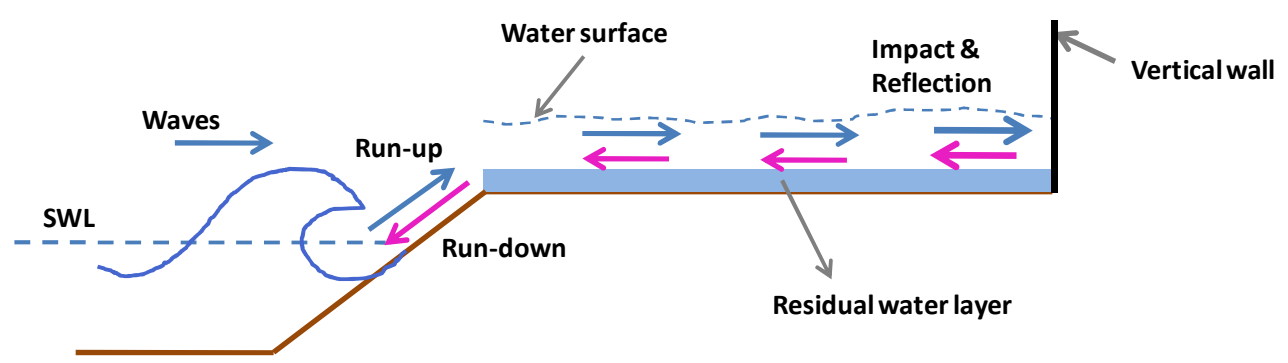

Figure 7. Hydrodynamic processes associated with the impact of the overtopping bore on the dike crest

\section{Pressure-time history}

An example of pressure-time history recorded at the location P2 of the vertical wall is shown in Fig. 8. Although the generated waves in one test are nominally identical, their impact behaviour varies significantly. The highly stochastic nature of the impact pressures on the vertical wall is a well known characteristic of the impact load, and has been already reported by many authors (eg. Bagnold, 1939; Bullock et.al., 2007; Hattori et.al., 1994). Such variation is likely due to the following main reasons as reported by Kisacik et.al (2010);

- Turbulence left behind by a preceding wave

- Strong interaction with the reflection of the preceding wave

- Interaction of the residual water layer with the incoming waves

- Influence of entrained air

Within the same test run different impact types can be seen in the pressure time history. The main type of impact is in between turbulent bore and slightly breaking wave according to the classification by Oumeraci et al, (1993). Nevertheless high impact pressures are also recorded during some of the tests. A detail view of the highest peak pressure in Fig. 8 is given below over time duration of an impact (see Fig. 9). It shows a double peak profile with a high peak of short duration (dynamic impact pressure) followed by a more slowly varying peak (quasi-static pressure). The shape of the pressure signal represents a typical impact profile, which is also nicknamed as 'church roof' (Oumeraci et al, 2001, Peregrine, 2003). The first peak is due to the impact of the bore crest, which causes for a sharp increase in dynamic pressure. The dynamic pressure drops immediately after the impact, and there is a secondary peak pressure which is the maximum quasi-static pressure due to the maximum run-up of the water body. The highest impact pressure of $32.85 \mathrm{kPa}$ which was recorded at P2 with the rising time of 
$18 \mathrm{~ms}$, represents the shortest impact during the experiment (Fig. 8). There is no significant pressure oscillations observed just after the first peak pressure. In this experiment, the wave is already broken on the dike slope, and the air entrainment is just in the form of air bubbles in the turbulent bore. Therefore, there is no air pocket entrapped between the wall and the impinging wave crest.

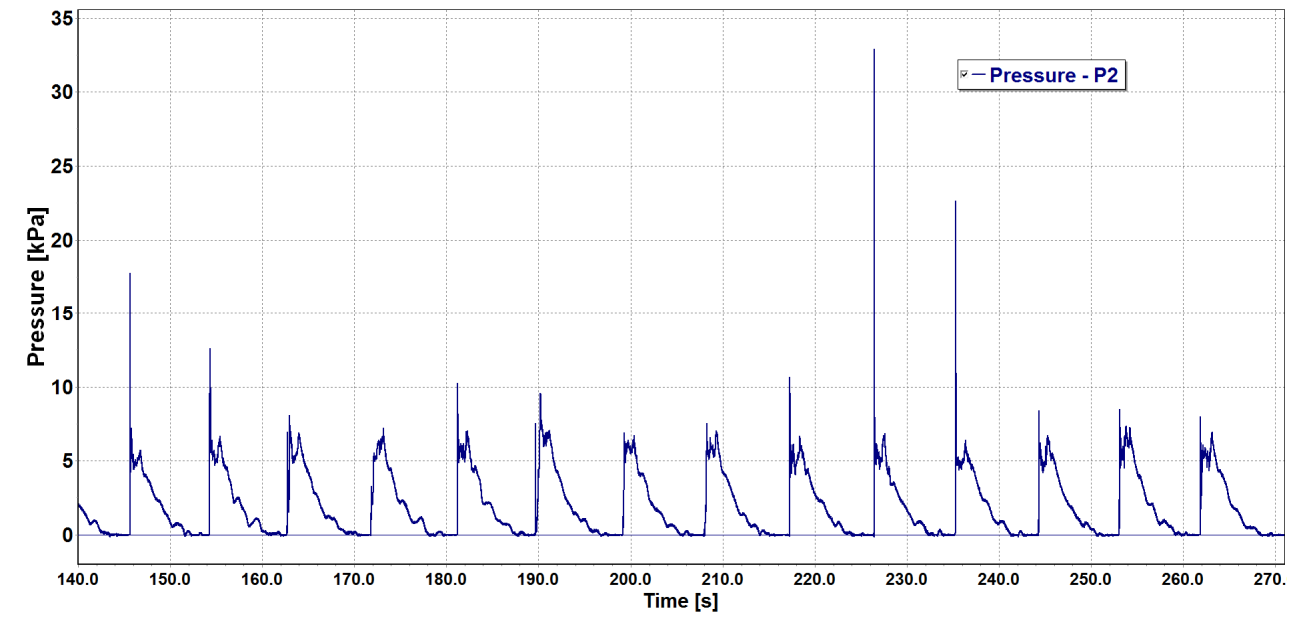

Figure 8. Pressure-time history recorded at P2 (see Fig. 5) during test no 06 (see Table 1)

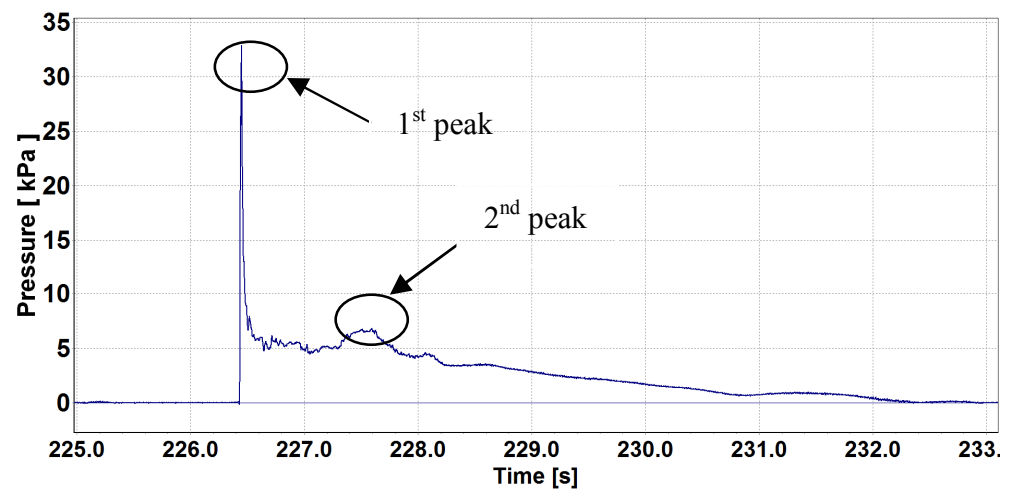

Figure 9. Time history of the highest impact pressure $\left(10^{\text {th }}\right.$ peak in Fig. 8$)$

A detail view of a lower pressure peak in Fig. 8 is given in Fig. 10 over a period of wave. In this case, the dynamic pressure component is not dominating the quasi-static pressure. This can be due to lower velocity of the impinging bore and higher residual water layer in front of the wall, which cause a reduction of the dynamic peak pressure (lower $1^{\text {st }}$ peak) and an increased static pressure $\left(2^{\text {nd }}\right.$ higher peak).

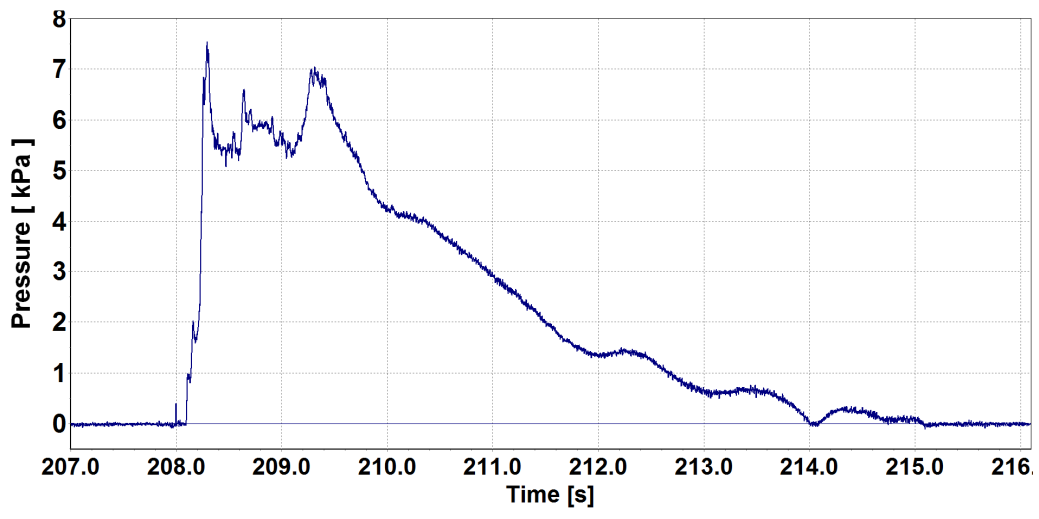

Figure 10. Time history of a lower impact pressure $\left(8^{\text {th }}\right.$ peak in Fig. 8$)$ 
An example of simultaneous pressure recordings of one impact from the 8 pressure sensors (PDCR) along the wall height during test no 04 is shown in Fig. 11, which results in the highest total force on the wall. The locations of the pressure sensors at the wall are indicated in Fig. $5 \mathrm{~b}$ and $5 \mathrm{c}$. The corresponding flow depth of the incoming bore just in front of the wall is $70 \mathrm{~cm}$ in this example, which reaches the bottom four sensors. The pressure records of the bottom four sensors (P1 to P4) show a distinct double peak. The first higher peak corresponds to the wave hitting the wall, while the second lower peak represents the quasi-static pressure due to the maximum wave run-up. Pressure sensors P1 to P4 correspond to elevations where higher dynamic pressures tend to occur, since those four sensors are affected in a direct way by the impact. Sensor P1 always shows a small residual pressure just before the impact, which is due to the remaining water layer on the dike crest. Furthermore, the upward splash with spray results in irregularities on the signals of the upper sensors (P5 to P8). The upper sensors also indicate a very small negative pressure just before the impact, which is due to very high velocity of the up rushing jet that causes the pressure drops below the atmospheric pressure value. But this negative pressure is not significant compared to the positive peak. As compared to the bottom sensor profiles, the pressures on the upper sensors (P5 to P8) drop quickly due to high downward acceleration of the jet.

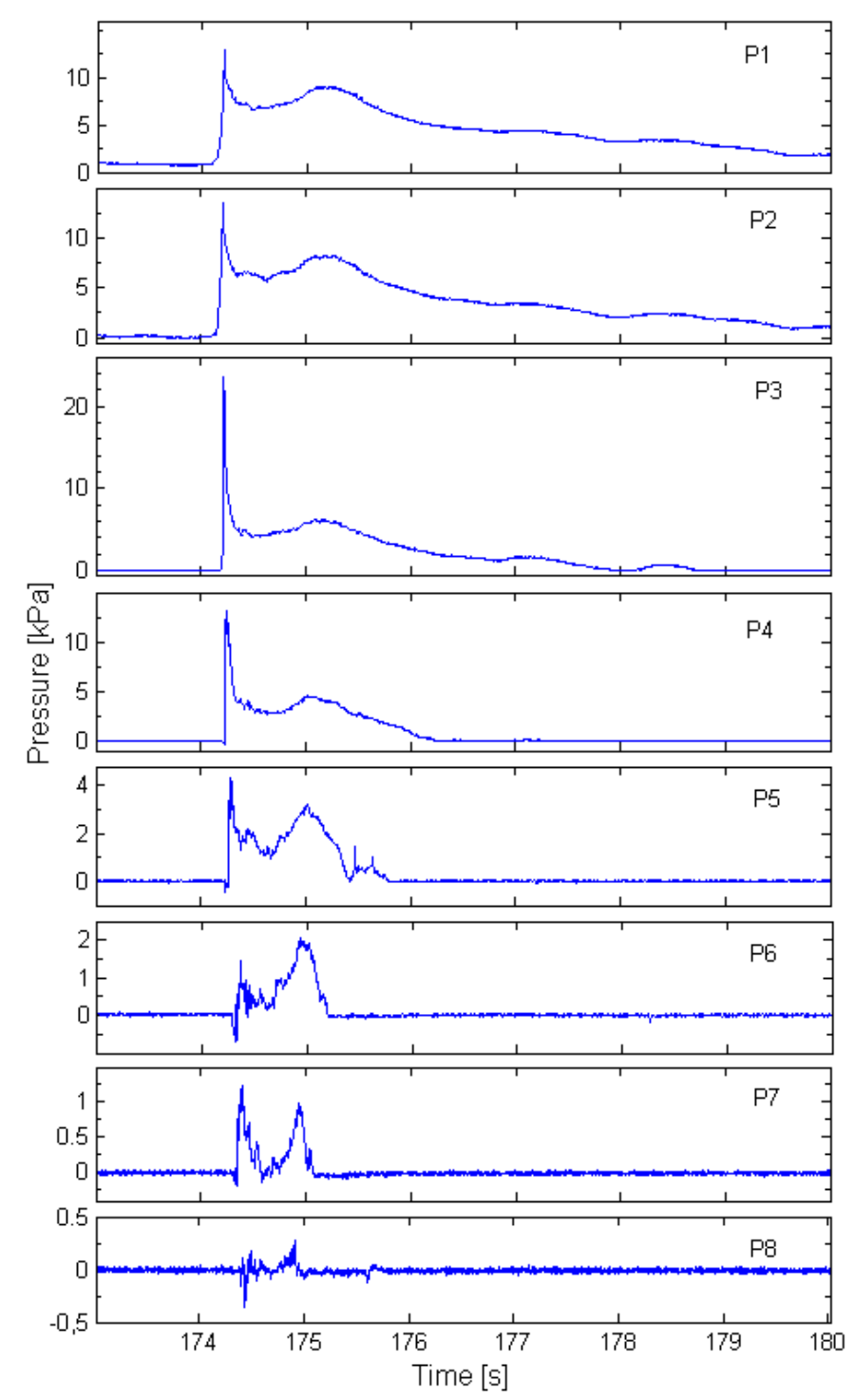

Figure 11. Simultaneous pressure records measured at different elevations at the wall resulting in the maximum total force 
Impact force obtained from pressure measurements

Total forces induced by the overtopping bore on the wall are obtained directly from the force sensors and indirectly by integrating the simultaneous pressure records as shown for instance for pressure sensors P1-P8 in Fig. 11. The rectangular integral method is applied as shown in Fig. 12. Pressure distribution between the sensors is assumed to be uniform. Comparison of integrated pressures and simultaneously measured forces using force transducers will provide an assessment of the validity of the pressure integration.

The force $F_{\text {int }}(\mathrm{N} / \mathrm{m})$ resulting from discrete pressure integration is given by the following expression:

$$
F_{\text {int }}=P_{1}(t) *\left[\Delta z_{1}+\Delta z_{2} / 2\right]+\left[P_{8}(t) * \Delta z_{8}\right]+0.5 * \sum_{i=2}^{i=n-1} P_{i}(t) *\left[\Delta z_{i}+\Delta z_{i+1}\right]
$$

Where $P_{i}(t)$ is the measured instantaneous pressure at the location of the $i$-th sensors (in $\mathrm{Pa}$ ), $\Delta \mathrm{z}_{i}$ are the distances (in $\mathrm{m}$ ) between two sensors as indicated in Fig. $5 \mathrm{c} . n$ is the number of pressure sensors.

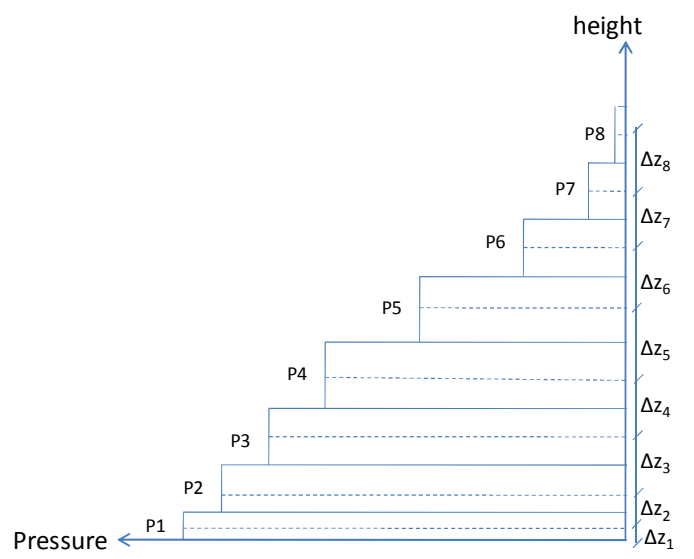

Figure 12. Illustration of pressure integration method

There were no differences found in the results obtained by above method compared to the trapezoidal integration method. A force time history obtained from the pressure integration (eq. 1) for test no 04 is shown in Fig. 13. The highest force peak is obtained with $F_{\text {int }}=7.6 \mathrm{kN} / \mathrm{m}$ for this test. It can be seen that the variations in the force peaks within the same test is less significant compared to the variations in the pressure peaks shown in Fig. 8, where only the sensor P2, located in the impact zone of the overtopping bore, was shown.

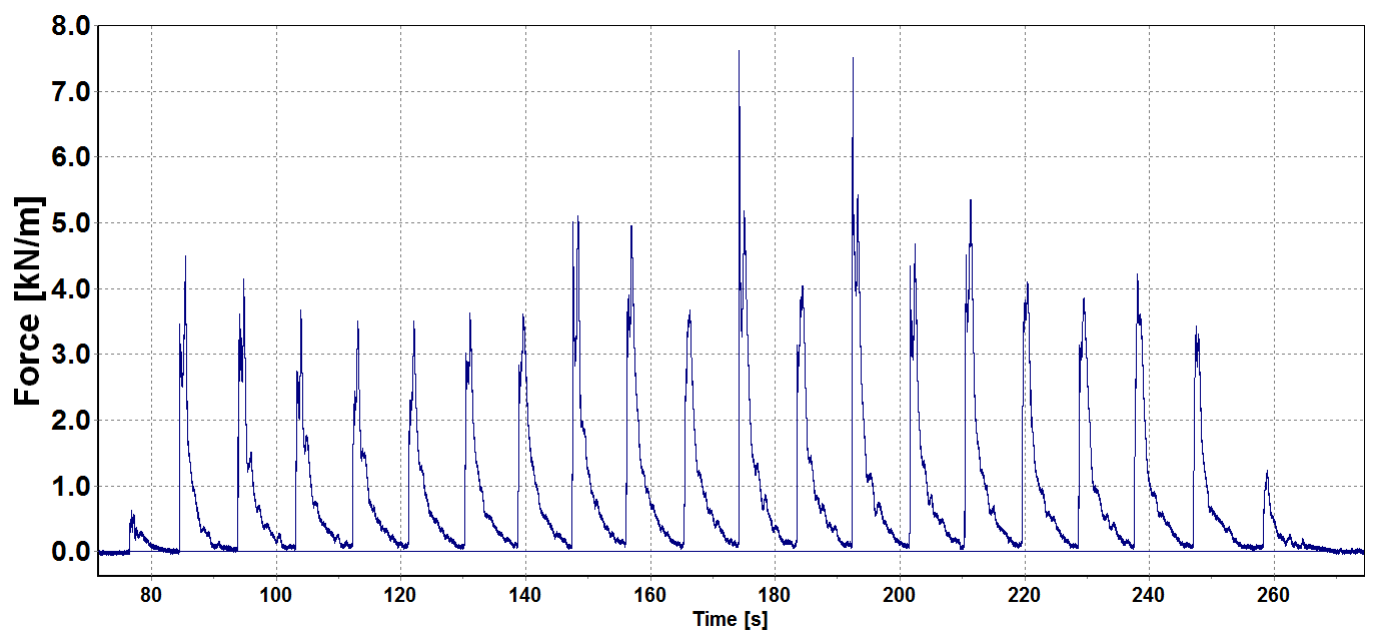

Figure 13. Time history of the total force on the wall obtained from the integration of simultaneous pressure records at different elevations at the wall 


\section{Impact force by force measurements}

The forces obtained on left and right walls are summed up in order to determine the total forces on each wall (see Fig. 14). There are 12 force sensors on the left wall; the forces measured on each plate are indicated as $F_{h 1}$ to $F_{h 12}$. Initially the forces on each plate are summed up and total forces on individual plates are calculated per $\mathrm{m}$ width, then all three forces are added to find the total force on the left wall ( $F_{L}$ see eq. 2$)$.

$$
\boldsymbol{F}_{\boldsymbol{L}}=\mathrm{FH} 1+\mathrm{FH} 2+\mathrm{FH} 3
$$

Where FH1, FH2 and FH3 are the total forces per meter width of bottom, middle and top plate of the left wall.

In a similar manner as for the left wall, forces recorded at the right wall $\left(\mathrm{F}_{\mathrm{v} 1}\right.$ to $\left.\mathrm{F}_{\mathrm{v} 4}\right)$ are summed up and then total forces are calculated per meter width $\left(F_{R}\right.$ see eq. 3). This enables the direct comparison of the total forces $(\mathrm{kN} / \mathrm{m})$ with the results obtained from pressure integration $(\mathrm{kN} / \mathrm{m})$.

$$
\boldsymbol{F}_{\boldsymbol{R}}=\mathrm{F}_{\mathrm{v} 1}+\mathrm{F}_{\mathrm{v} 2}+\mathrm{F}_{\mathrm{v} 3}+\mathrm{F}_{\mathrm{v} 4}
$$
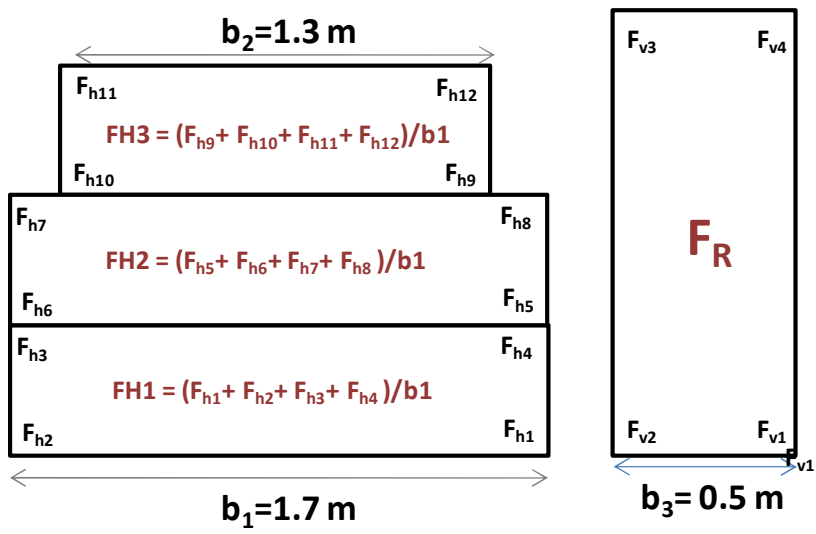

Figure 14. Illustration of force integration

Examples of the force measurements on the right and the left walls are presented in Fig. 15 and Fig. 16, respectively. The left y-axis indicates the recorded forces from individual sensors expressed in $\mathrm{kN}$, and the y-right axis shows the total forces on the wall calculated per meter width $(\mathrm{kN} / \mathrm{m})$. Forces obtained at the left and right walls display similar variation over the time, except the top sensors on the right wall show a very small negative force at the instant of impact. Since the impact is mainly located at the bottom of the plate, the vertical plate rotates a bit and the top sensors show a small pulling force. This effect is less visible in the horizontal plates, since they are separated by a joint at $0.5 \mathrm{~m}$ high.

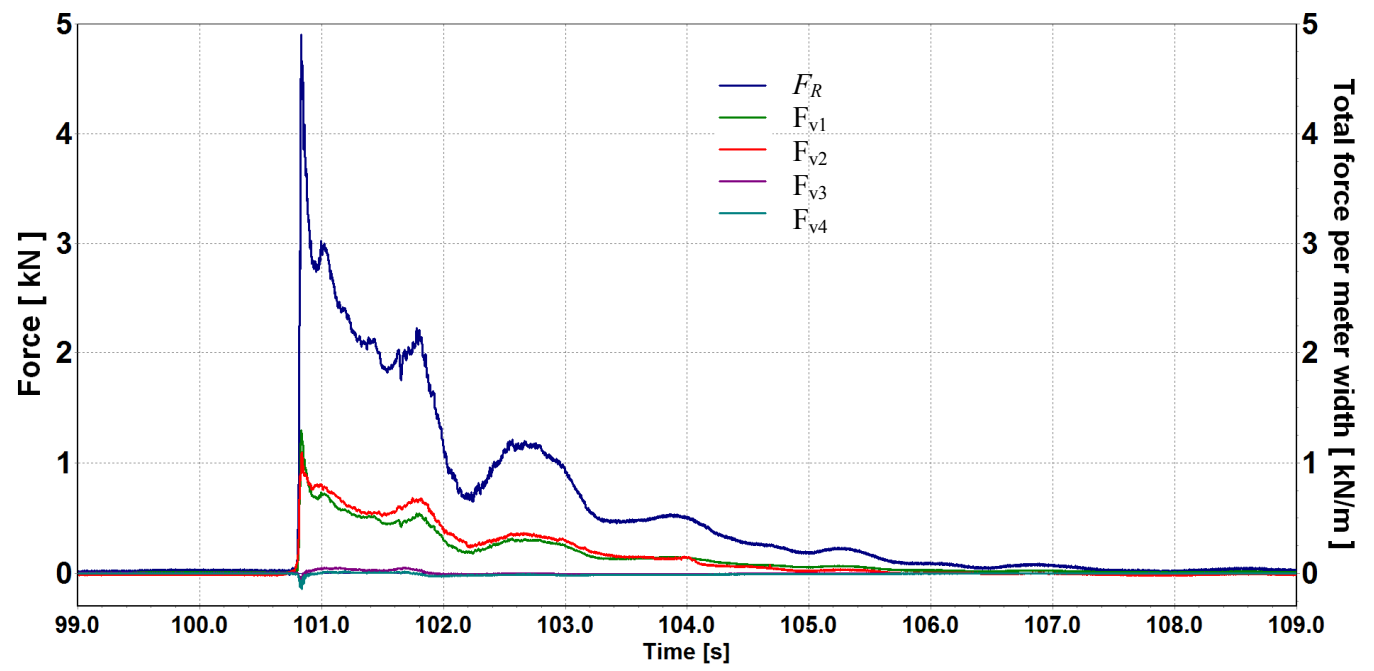

Figure 15. Time history of the forces recorded at the right wall ( $0.5 \mathrm{~m}$ wide) 


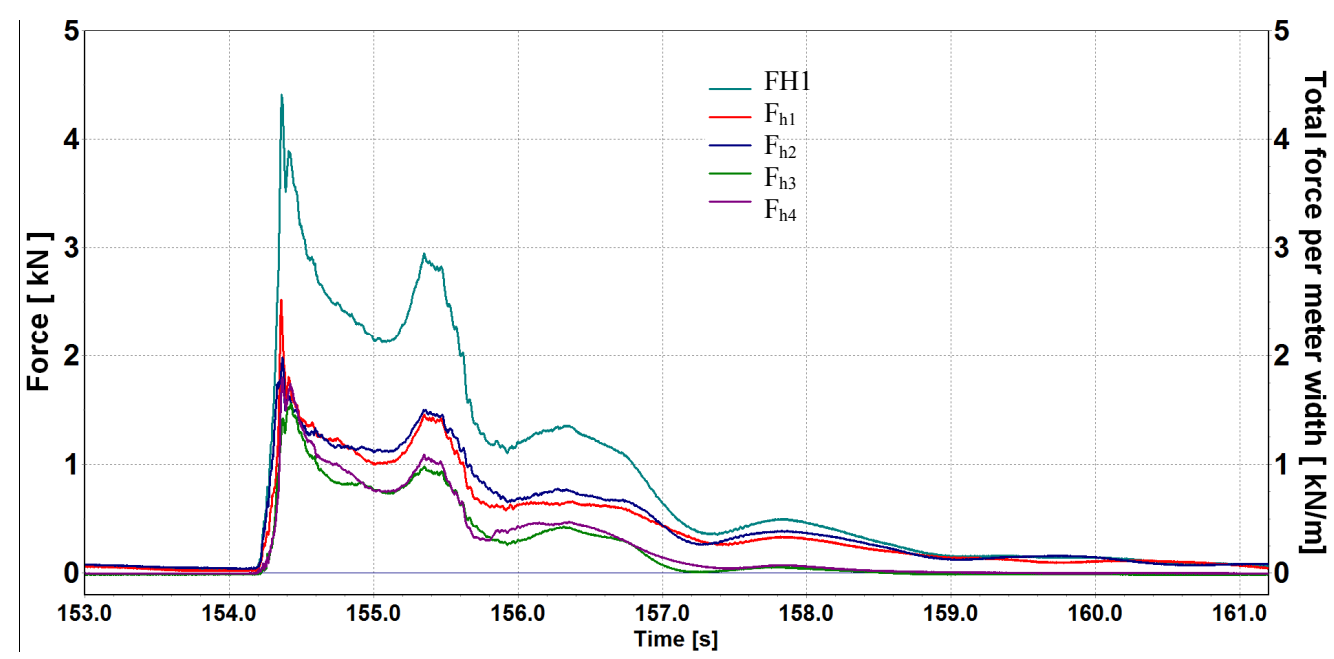

Figure 16. Time history of the forces recorded at the left wall (bottom plate, $1.7 \mathrm{~m}$ wide)

Force-time history obtained at three plates of the left wall is presented in Fig. 17. The bottom plate experiences the highest force (FH1) as it is exposed to a direct impact of the overtopping bore. Phase differences are clear between the peak forces of three plates. As the force on the bottom plate (FH1) reaches its maximum, run-up over the middle plate starts to occur which increases the force FH2. Once the maximum run-up is reached, the dynamic part of bottom and middle plates decreases together with stable quasi-static part. The second hump is due to the increase in dynamic part (compensating the decrease of the static part due to the lower water level) as the water is rushing down. The upper plate (FH3) does not feel any significant forces. The total force (FL) is dominated by the forces on the bottom plate (FH1).

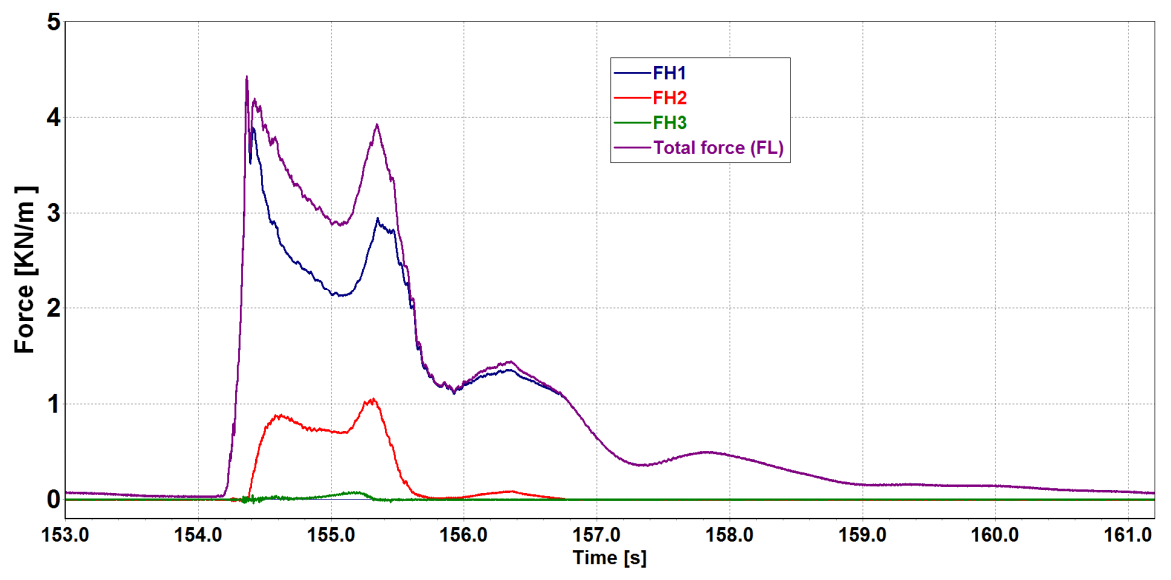

Figure 17. Force recordings of an impact at three plates of the left wall

\section{Pressure distribution}

Fig. 18 shows "local" (in red) and instantaneous pressure distributions at the wall (in blue and green) obtained for test 04 . The "local" peak pressure profile represents the envelope of the maximum pressures recorded by all individual sensors recorded for all the impact events. The instantaneous pressure profile represents the distribution of pressures occurring simultaneously at the instant of maximum total force (in blue) and at the instant of maximum quasi-static component (green). The black line in Fig. 18 represents the average residual water layer thickness in front of the wall just before the impact occurs. The "local" peak pressure profile is different and gives higher forces compared to the pressure profile at the instant of the maximum total force. The same trend is observed for all other tests as well. This is because the maximum values of individual sensors do not necessarily occur at the moment of highest impact. Local peak pressure profile may not be important for the whole structural integrity, but it may be important in the case of any damage or crack exists (Kisacik et.al., 2012). 
Both "local" and instantaneous pressure profiles indicate that the locations at P2 and P3 (15 cm and $35 \mathrm{~cm}$ ) are the most sensitive to high impact pressures. The upper wall (above $0.55 \mathrm{~m}$ ) is mainly exposed to forces due to the run-up and no dynamic peaks due to the actual impact, therefore, it is less vulnerable to the higher dynamic loads. The pressure distribution at the instant of maximum quasistatic force (green line) indicates a smooth variation over the height. The maximum quasi-static pressure is located at the bottom of the wall and it reduces towards the wall height.

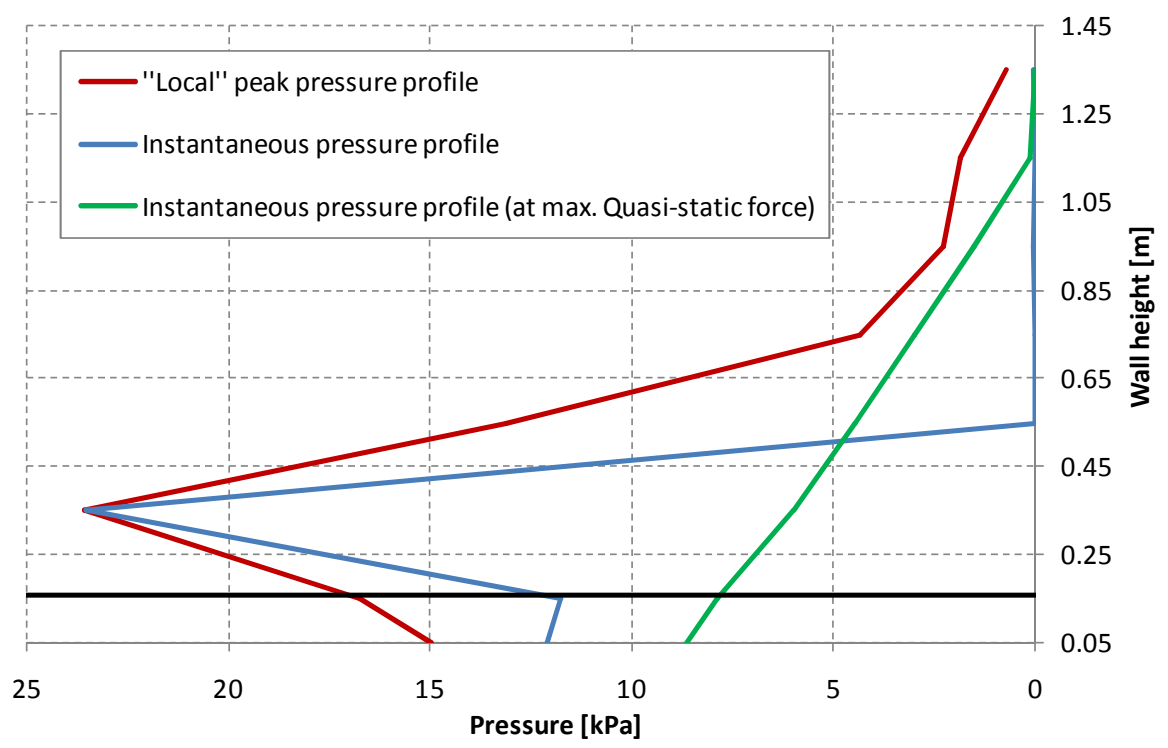

Figure 18. Pressure distribution along the wall height

\section{Comparison of integrated pressures and total forces}

Forces obtained indirectly by means of pressure integration (left plate of the right wall) are compared with the total forces obtained from direct force measurements at the right wall (right plate). Since the both plates of the right wall have the same dimensions, so no influences of this will be included in the results. The comparison will provide a better insight into both measuring methods used for the impact force measurements. As described below, the comparison is made separately for the two model setups tested: partially and fully blocked wall.

\section{a.) Fully blocked wall}

The highest peak force $\left(F_{\text {int }}=7.6 \mathrm{kN} / \mathrm{m}\right.$ ) was obtained during Test no 04 with $1.5 \mathrm{~m}$ wave height and $9 \mathrm{~s}$ period (see Table 1). A direct comparison of the peak force-time history obtained by pressure integration and from force transducers is shown in Fig. 19.

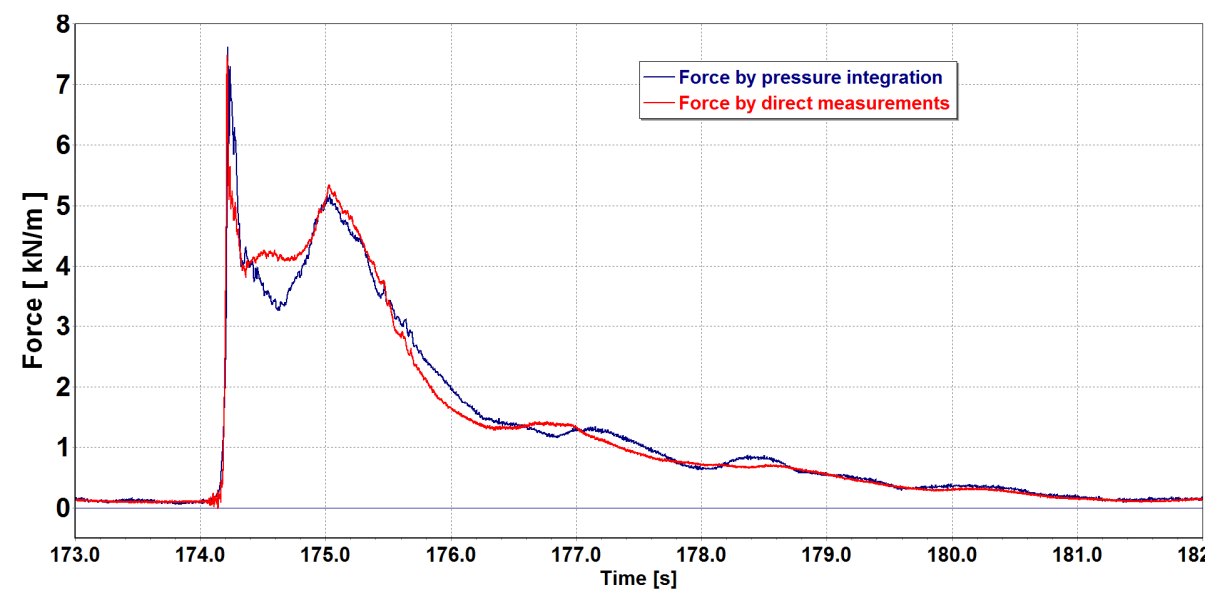

Figure 19. Force histories obtained by pressure integration and by direct force measurements for the fully blocked wall 
The force distribution over the time is in good agreement with the integrated pressures including the peak values. Both pressure and force sensors recorded a double peak profile, which reflects a church roof shape as described in the literature (Oumeraci et al, 2001). The first peak corresponds to the dynamic component of the impact load, and the second peak to the quasi-static component associated with the maximum wave run-up.

The peak forces obtained by pressure integration and those obtained by direct force measurements in Tests no 01, 02, 03 and 04 for fully blocked wall conditions (see Table 1) are plotted for comparison in Fig. 20. Generally a very good agreement is found between the forces obtained by the two methods. It is concluded that for the tested conditions the structure response recorded by the force transducers corresponds approximately to the wave loading on the wall recorded by the pressure sensors.

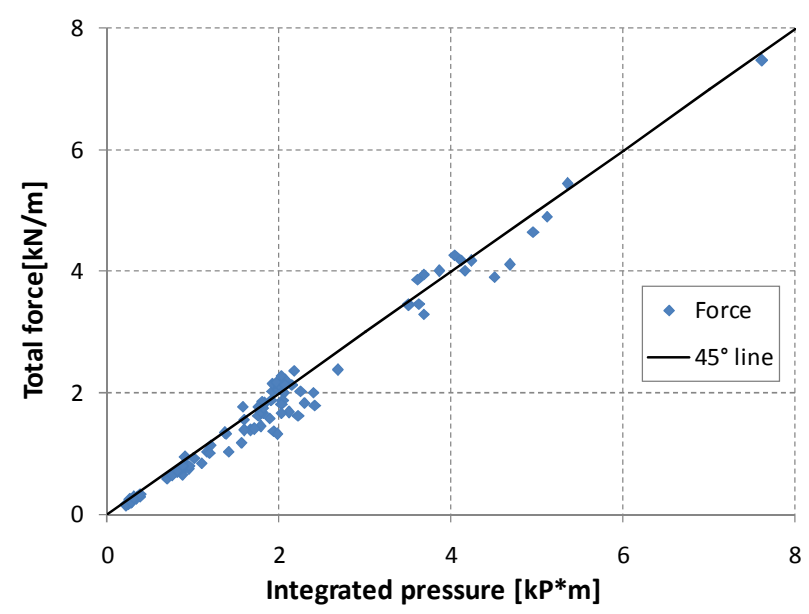

Figure 20. Peak force obtained by pressure integration and by direct force measurements for the fully blocked wall

\section{Partially blocked wall}

Similar to the comparison in Fig. 18 for the fully blocked wall, a comparison of the force-time histories obtained from Test no 06 for the partially blocked wall is shown in Fig. 21.

Though the shape of the force-time histories obtained by both methods is similar, the force peaks obtained by pressure integration are slightly higher than those obtained by direct force measurement. In this case, the response of the structure recorded by the force transducers does not perfectly correspond to the wave loading of the wall.

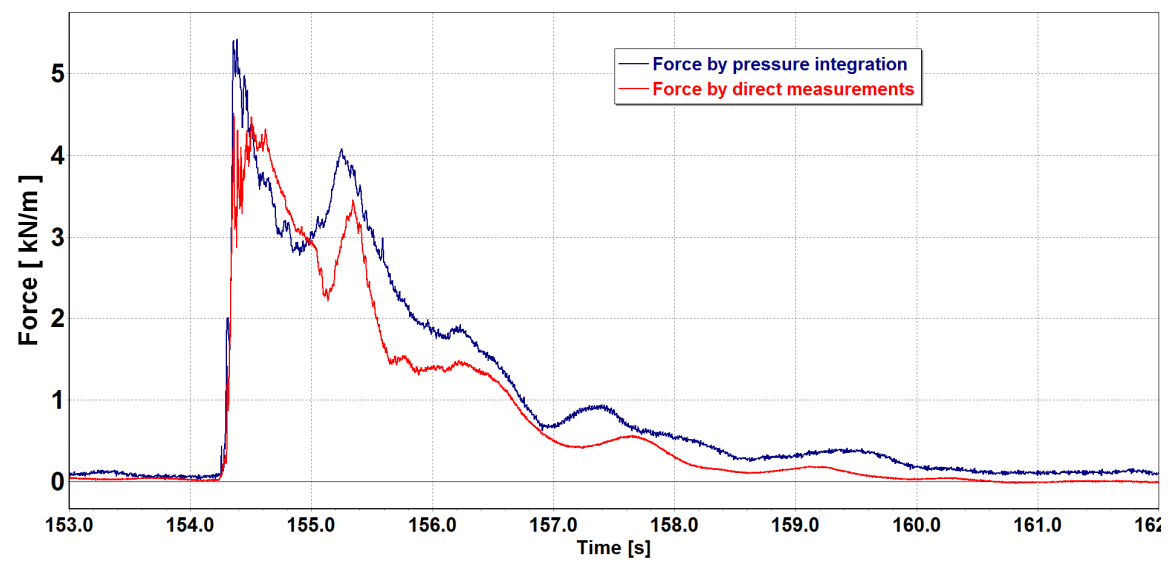

Figure 21. Force histories obtained by pressure integration and by direct force measurements for the partially blocked wall

Another visualisation of the deviations of the peak forces obtained by the two methods is shown Fig. 22. The difference is more pronounced for the higher range of the forces (up to 35\%). Pressure 
integration gives a higher total force compared to direct force measurements. Several reasons for these deviations are possible.

There is a residual water layer behind the wall was observed during the experiments in the case of partially blocked wall. This exerts a hydrostatic force component on the wall in the opposite direction, which reduces the measured total force. As force transducers record directly the response of the entire structure, the hydrostatic component in opposite direction is also recorded. In contrast, the water layer behind the wall has no influence on the pressure measurements on the wall front.

Another reason could be the side wall effect, which may not fully minimised by the $10 \mathrm{~cm}$ strips along the sides of the wall (see Fig. 6, left). When the flow goes around the wall, part of the kinetic energy is transmitted through the gaps, which contributes to the force reduction due to Bernoulli's effect. Pressure sensors (PDCR) are placed in the middle of the wall, relatively far from the edges of the wall, and measure on a much smaller surface $\left(\mathrm{ca} .2 \mathrm{~cm}^{2}\right)$. They are therefore less affected by the side wall effects.

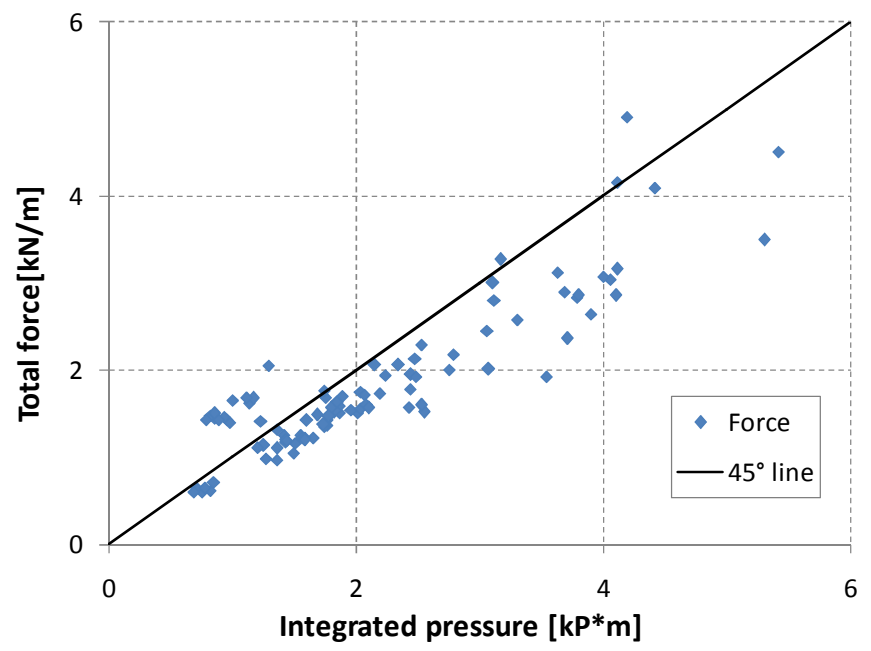

Figure 22. Peak force obtained by pressure integration and by direct force measurements for the partially blocked wall

As mentioned above, Tests no 03 and 04 for the fully blocked wall set up are repeated during the partially blocked wall setup (respectively tests no 05 and 06 in Table 1). In order to analyze the differences in the results obtained by the pressure and force sensor measurements for the fully and partially blocked wall setups, the peak forces obtained by each method during each test are averaged. The very high force peaks, which occur exceptionally, are excluded in the average calculations since they can lead to wrong interpretation of the averaged values. Table 2 attempts to summarise the averaged peak forces obtained in the two repeated test conditions for the fully and partially blocked wall cases.

\begin{tabular}{|c|c|c|c|c|}
\hline \multicolumn{5}{|c|}{$\begin{array}{c}\text { Table 2. Comparison between the averaged peak forces obtained by } \\
\text { pressure integration and force measurement (kN/m) }\end{array}$} \\
\hline \multirow{2}{*}{ Test conditions } & \multicolumn{2}{|c|}{ Fully blocked wall } & \multicolumn{2}{c|}{ Partially blocked wall } \\
\cline { 2 - 5 } & Pressure Int. & Force M & Pressure Int. & Force M \\
\hline $\begin{array}{c}\text { Hs:=1.13m, Tp =9s } \\
\text { (Tests.03 and 05) }\end{array}$ & 2.01 & 2.08 & 1.97 & 1.59 \\
\hline $\begin{array}{c}\text { Hs }=1.50 \mathrm{~m}, \mathrm{Tp}=9 \mathrm{~s} \\
\text { (Tests.04 and 06) }\end{array}$ & 4.16 & 4.07 & 4.06 & 3.40 \\
\hline
\end{tabular}

Under both test conditions, the averaged peak forces obtained by both methods are, as explained above, almost similar in the case of fully blocked wall, whereas they differ more in the case of partially 
blocked wall. Pressure integration provides similar results under both fully and partially blocked wall conditions for both test conditions. In contrast, the results obtained from the direct force measurement show a reduction of peak force per meter width $(\mathrm{N} / \mathrm{m})$ up to $20 \%$ when the wall is open.

\section{Comparison of forces per meter width on the left and right walls}

The forces per meter width on the left $\left(F_{L}\right)$ and right walls $\left(F_{R}\right)$ are calculated by eq. 2 and eq. 3 respectively. The force peaks obtained on left and right wall then are compared under fully and partially blocked wall conditions as shown in Fig. 23. Generally, a good agreement can be seen in the lower force ranges, yet there are some scatters in the higher force ranges where deviation up to $30 \%$ are observed.

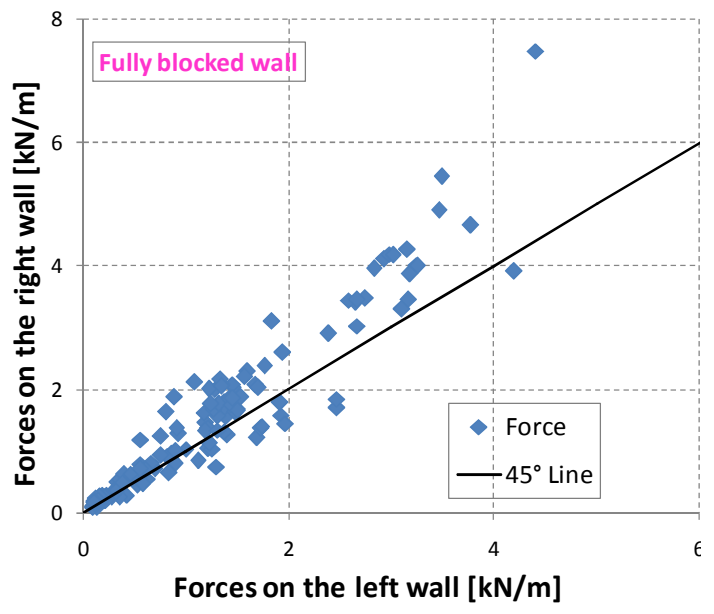

(a) Fully blocked wall set up

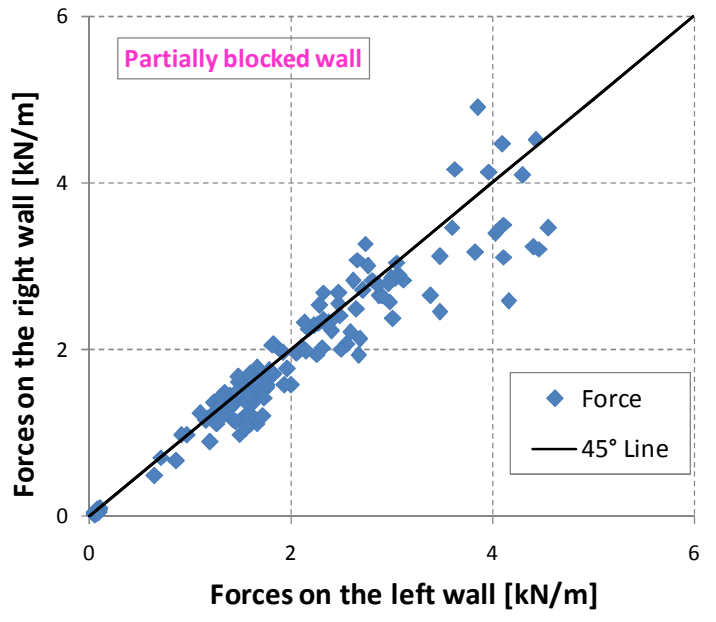

(b) partially blocked wall set up

Figure 23. Maximum forces on the left and on the right wall for the fully blocked wall set up (a) and for the partially blocked wall set up (b)

For the fully blocked wall case (Fig .22a), there are some force peaks on the right wall higher than the on the left wall. For the partially blocked wall case (Fig .22b), however, most of the higher peaks are higher on the left wall than on the right wall. This shows there is no systematic variation of the peak forces in the horizontal direction. The reason for the above variation could be due to local peaks, which results from a splash of water. Another reason is the variation in the velocities of the turbulent overtopping bore, which is not everywhere the same over the width of the bore, leading to some scatter in the measured impact forces on the left and right wall. There can be other reasons as well, which are not clear yet.

\section{CONCLUDING REMARKS}

Simultaneous measurements of the loads induced by an overtopping bore on a vertical wall are performed by using both force and pressure transducers in the Large Wave Flume (GWK) in Hannover. The bore is generated as a result of a wave overtopping over a broad crested sea dike and propagating as a bore towards a vertical wall located on the dike crest. The entire loading process at the vertical wall due to overtopping bore is highly complicated because of the high reflection and the residual water layer on the dike crest. The results obtained from pressure and force sensors are comparatively described.

Analysis of pressure-time history reveals that the impact pressures induced by overtopping bore are highly stochastic even within the same test with regular waves. The peak pressure profile consists of a dynamic and quasi-static component. The dynamic peak is nearly always higher compared to the quasi static part, and a "church roof" pressure recording is found. The "local" vertical pressure distribution (envelope of all pressure sensors) is different and leads to higher forces compared to the instantaneous pressure distribution at the instant of maximum total force. The highest peak of an individual sensor does not always occur at the impact with the highest total loading. Nevertheless, both local and instantaneous pressure profiles indicate that the locations at pressure transducers $\mathrm{P} 2$ and $\mathrm{P} 3(10 \mathrm{~cm}$ and $35 \mathrm{~cm}$ heights) are more sensitive to high impact loads. 
Essentially the pressure sensor measures the actual loading of impact regardless the characteristics of the structure. The force sensor, on the other hand, measures the response of the structure to an impact. Despite different measuring principles, a good agreement was found between the forces obtained by the pressure integration and the directly measured forces for a continuous wall (fully blocked wall setup). However, when the wall is open, the response of the structure recorded by the force sensors gives lower values compared to the impact loads measured by the pressure sensors. The possible reasons for the differences are discussed. Comparison of the forces across the width of the flume indicates that the spatial pressure distribution is highly stochastic due to the variation in flow velocities of the turbulent bore, also in the horizontal direction.

Further research is imperative for deeper understanding of the processes and mechanisms related to the impact loads induced by overtopping bores. Identifying the most relevant parameters of the bore and relating them to the impact loads on the one hand, and wave conditions on the other hand are the future challenges.

\section{REFERENCES}

Bagnold, R.A., 1939. Interim report on wave-pressure research. Proceedings of the Institution of Civil Engineers 12, 201-226.

Bullock, G.N., Obhrai, C., Peregrine, D.H., Bredmose, H., 2007. Violent breaking wave impacts Part 1: results from large-scale regular wave tests on vertical and sloping walls. Coastal Eng. 54 (8), 602617.

CEM, 2003. Coastal Engineering Manual, Part VI, Chapter 5, Engineer Manual 1110-2-1100, U.S. Army Corps of Engineers, Washington, DC.

De Rouck, J., Van Doorslaer, K., Versluys, T., Ramachandran, K., Schimmels, S., Kudella, M., Trouw, K., 2012. 'Full scale wave impact tests on a vertical wall in the large wave flume in Hannover', ICCE (accepted).

Hattori, M., Arami, A., Yui, T., 1994. Wave impact pressure on vertical walls under breaking waves of various type. Coastal Eng. 22 (1-2), 79-114.

Kisacik, D., Troch, P., Van Bogaert, P., 2010. Experimental results of breaking wave impact on a vertical wall with an overhanging horizontal cantilever slab. 32nd International Conference on Coastal Engineering (ICCE), Shanghai, China.

Kisacik, D., Troch, P., Van Bogaert, P., 2012. Description of loading conditions due to violent wave impacts on a vertical structure with an overhanging horizontal cantilever slab. Coastal Engineering. 60 (1), pp. 201-226.

Oumeraci, H., Klammer P., Partenscky, H.W., 1993. Classification of breaking wave loads on vertical structures. Journal of Waterway, Port, Coastal and Ocean Engineering, ASCE, vol. 119, no. 4, pp. 381-397.

Oumeraci, H., Kortenhaus, A., Allsop, N.W.H., De Groot, M.B., Crouch, R.S., Vrijling, J.K., Voortman, H.G., 2001. Probabilistic design tools for vertical breakwaters. Rotterdam, The Netherlands: Balkema, $392 \mathrm{p}$.

Peregrine, D.H., 2003. Water-wave impact on walls. Annual Review of Fluid Mechanics 35, $23-43$.

Ramachandran, K., Roldan Genzalez, R., Schimmels, S., Oumeraci, H., Van Doorslaer, K., 2012. 'Impact loads on a vertical wall due to overtopping bore - Large scale physical model experiments'. Coastlab 2012, Ghent, Belgium.

Van Doorslaer, K., De Rouck, J., Trouw, K., van der Meer, J.W., Schimmels, S., 2012. 'Wave forces on storm walls, small and large scale experiments', Proceedings of COPEDEC VIII, Chennai, India.

Verwaest, T., Vanpoucke, P., Willems, M., \& Mulder, T. D. (2010). Waves overtopping a wide-crested dike. Coastal Engineering 2010, (pp. 1-9). 